\title{
A PEQUENA PRODUČ̃̃O AVÍCOLA FAMILIAR E O SISTEMA DE INTEGRAÇÃO NO OEȘTE CATARINENSE: "uma prisão de portas abertas" 1
}

\author{
Claudia Mazzei Nogueira* \\ Edivane de Jesus ${ }^{* *}$
}

\begin{abstract}
Esse texto é parte da pesquisa sobre a divisão sexual do trabalho dos pequenos avicultores familiares inculados ao Sistema de Integração das agroindústrias, no contexto da reestruturação produtiva. Para tanto, o texto analisa o referido sistema na avicultura no Oeste Catarinense, contemplando alguns elementos das metamorfoses que vêm ocorrendo no mundo do trabalho e como elas vêm intensificando a precarização do pequeno produtor rural familiar no segmento da avicultura.

Palavras-Chave: Agroindústria. Relações de trabalho. Pequeno produtor rural familiar. Sistema de integração. Precarização.
\end{abstract}

\section{INTRODUÇÃO}

O amplo processo de reestruturação produtiva, ao metamorfosear o mundo do trabalho, não atingiu somente os/as trabalhadores/as das indústrias que se encontram na área urbana, mas, também, os do setor agrário, de que é exemplo importante o setor da agroindústria vinculado à avicultura.

É fato que a agroindústria, no setor alimentício, viveu e ainda continua vivenciando um acentuado processo de reestruturação produtiva que, em grande medida, é resultado do avanço tecnológico e das novas formas de organização da produção, bem como da logística das

* Doutora em Serviço Social. Professora do Departamento de Saúde, Educação e Sociedade no Curso de Serviço Social e do Programa de Pós-Graduação Interdisciplinar da Universidade Federal de São Paulo - UNIFESP-BS.

R. Silva Jardim, 136. Vila Mathias. Cep: 11015-020. Santos - São Paulo - Brasil. mazzeinogueira@uol.com.br

* * Mestre em Serviço Social pela Universidade Federal de Santa Catarina - UFSC. edivanejesus@hotmail.com

${ }^{1}$ Este texto integra o projeto de pesquisa Bolsa Produtividade da Prof ${ }^{a}$ Dra $^{\text {a }}$ Claudia Mazzei Nogueira, com o título "A Divisão Sexual do Trabalho e da Reprodução no Sistema de Integração da Produção de Aves do Oeste Catarinense”, que está sendo realizada com o apoio do CNPq. Ele conta com a participação das pesquisadoras Edivane de Jesus, Mailiz Lusa e Maria Aparecida dos Santos. empresas, conforme a terminologia empresarial. Esse processo, similarmente ao que ocorreu no setor urbano, iniciou-se no espaço produtivo agrário no final dos anos 1970. Dentro da agroindústria, mais especificamente na área de alimentos, as alterações na forma de produção foram claras. Segundo Walter Belik (1994, p. 59)

O esgotamento do modelo "fordista" começou a se fazer sentir tanto pelo lado da produção como pelo lado do consumo. Formas organizativas ultrapassadas levavam a que a indústria fosse obrigada a atuar em escalas gigantescas diversificando sua produção horizontalmente, abrangendo uma enorme gama de itens; e verticalmente, integrando-se aos seus fornecedores e distribuidores. Pelo lado do consumo, a aparente saturação dos mercados nos países de renda alta fazia com que as taxas de crescimento do setor fossem bastante modestas. [...] A introdução da informática e, em menor grau, das biotecnologias revolucionou os métodos de produção, abrindo caminho para a utilização eficiente de menores escalas de produção e a uma diversificação das fontes de matérias-primas.

E complementa:

No que se refere aos aspectos organizativos, novos desenhos são colocados em ação. Mudam as 
relações entre fornecedores e distribuidores, influenciando uma verdadeira reconversão das relações em toda cadeia industrial. (Belik, 1994, p. 60).

Cabe lembrar que muitas das associações e fusões entre indústrias, tanto do setor urbano quanto do rural, iniciam seus acordos nesse período, respeitando, obviamente, os seus segmentos produtivos, suas especificidades regionais, as formas de concorrência etc., como é o caso da Sadia, empresa que foi objeto desta pesquisa.

No que se refere a este ramo, Belik (1994, p. 60) afirma corretamente que:

O elemento diferenciador da indústria de alimentos no processo de reestruturação em curso a partir dos anos 80 foi a capacidade deste segmento em se adaptar a um programa de produção flexível do tipo "just-in-time" [...]. De fato, dada a necessidade de estabelecer um largo tempo de colaboração com sólidos mecanismos de fixação de preços e pactuação de margens ao longo de toda a cadeia produtiva há uma ruptura do modelo "fordista" e a emergência de uma verdadeira solidariedade produtiva.

\section{E complementa:}

Novos métodos organizativos, definindo relações entre fornecedores e relações dentro das unidades produtivas, dão origem a um renovado ambiente produtivo. A flexibilidade proporcionada pelo novo sistema de trabalho trouxe vantagens inegáveis sobre a produção em massa diante de um mercado segmentado e altamente diversificado. (Belik, 1994, p. 61)

Dentro deste contexto, a intensificação da inserção da mulher no mundo do trabalho assalariado, nas últimas décadas, pode ser um dos exemplos da "flexibilidade" desse novo sistema e, assim, colaborar para o crescimento desse setor, através de uma maior produção de mercadorias nas indústrias de alimentos, pois, historicamente, a "responsável” pela atividade doméstica (na qual o ato de cozinhar se insere), é exercido centralmente pela mulher e, ao se ausentar do seu espaço reprodutivo para trabalhar no espaço da produção, o tempo dispensado às tarefas domésticas se reduz, propiciando, em boa medida, um maior consumo de produtos conge- lados, semiprontos (ou, ainda, já limpos e cortados), como é o caso do setor de aves.

Não é a toa que muitos pesquisadores/as desse ramo alimentício afirmam que a produção vem, a cada ano, ganhando mais espaço. Por exemplo, no setor de carnes de aves

[...] o consumo per capita de carnes brancas no Brasil saltou de 2,6 quilos por habitante, em 1970, para 10,9 quilos por habitante, em 1980, para mais de 14 quilos por habitante em 1993, superando assim o consumo de carne bovina no País (Belik, 1994, p. 67).

Outro fator que permitiu essa ampliação no consumo foi o avanço tecnológico, principalmente na fase de desenvolvimento das aves, ${ }^{2}$ ou seja, no trabalho de criação animal dos produtores integrados às empresas do setor, que hoje transforma, por exemplo, um pintinho em frango em média de 30 dias.

Cabe lembrar que este segmento de avicultura está localizado mais fortemente no Oeste Catarinense, motivo pelo qual optamos em pesquisar as condições de trabalho nas pequenas aviculturas familiares vinculadas ao denominado sistema de integração nessa região.

\section{O SISTEMA DE INTEGRAÇÃO NA PRODU- ÇÃO DE AVES DO OESTE CATARINENSE E SEU DESENHO}

Um dos segmentos que mais emprega na região do Oeste Catarinense é o da agroindústria, principalmente as vinculadas à produção de carnes de aves, suínos e bovinos, como as cidades de Chapecó, Concórdia e Joaçaba, consideradas como o maior polo produtor exportador de carne de aves do país.

Segundo Daniella Reche (2008, s/p), “[...] o Brasil tornou-se, nesses últimos 30 anos, o

\footnotetext{
2 No Brasil, no início dos anos 1970, um frango era abatido com 60 dias de vida; nos anos 1990 esse tempo diminuiu para 42/45 dias, alterando a taxa de conversão alimentar (sobre taxa de conversão alimentar ver a nota de rodapé ${ }^{\circ}$ 6 na p. 9) desse período de 3,0 para 2,4, ampliando os lucros empresariais. (Belik, 1994, p. 67).
} 
maior exportador de carnes de aves do mundo e o terceiro na produção [...]" dessa mercadoria, só ficando atrás dos Estados Unidos (16.162 mil toneladas) e da China (10.350 mil toneladas). "O país produz 9.335 mil toneladas de frango por ano e exporta 2.713 mil toneladas principalmente para a Ásia, Oriente Médio e Europa”. Essa liderança é consequência, centralmente, da atividade do polo agroindustrial pertencente à região do Oeste Catarinense, conforme já destacado anteriormente. Nesses municípios, encontramos as maiores indústrias do setor, entre elas as empresas Sadia S/A e Perdigão S/A, que se fundiram e formaram a empresa Brasil Foods, ${ }^{3}$ tornando-se uma das maiores produtoras e exportadoras mundiais de carne de frango, exportando para mais de 100 países no mundo.

O grande desenvolvimento econômico da Sadia em Chapecó ${ }^{4}$ foi decorrência da sua organização produtiva desde a sua implantação nos anos 1970, atraindo e incorporando pequenos produtores rurais, levando o setor industrial a compor um sistema de parceria, ou seja, a implementar o chamado sistema de integração. Segundo Reche (2008, s/p), o sistema de integração, hoje,

[...] assim como em todo o período agroindustrial na região, é o grande responsável pelo êxito da produção agroindustrial. Nesse sistema ocorre um esquema normativo de parceria entre o pequeno produtor rural e a empresa, na qual o primeiro produz para a indústria e esta se compromete com o fornecimento de assistência técnica

\footnotetext{
${ }^{3}$ Cabe, aqui, destacar que, em nosso texto, estaremos enfatizando o sistema de integração da indústria Sadia/ S.A., pois, apesar da fusão já ter sido formalizada e aprovada em 13 de julho de 2011 pelo Cade (Conselho Administrativo de Defesa Econômica), as relações ("parcerias") existentes entre os pequenos produtores integrados e uma das empresas, se mantêm totalmente independentes.

${ }^{4}$ Em 6 de março de 1971, na Assembleia Geral Extraordinária, a Sadia aprovou a abertura do capital, a mudança da razão social e a adaptação dos estatutos. A antiga S.A. Indústria e Comércio Concórdia deu lugar à nova Sadia Concórdia S.A. Indústria e Comércio, controladora de um grupo de cinco empresas do setor agroindustrial e comercial. Após essa alteração, a Sadia resolveu criar e abater perus, também de forma industrial, em seu frigorífico de Concórdia, por falta de espaço para instalar uma linha especial de abate de perus e, temendo problemas sanitários pela proximidade com a criação de frangos, instalou uma nova planta industrial em Chapecó, também no oeste catarinense. Desta forma, a Sadia Avícola de Chapecó foi inaugurada em 1973 (Teixeira, 1994; Dalla Costa, 2005).
}

e de insumos para a produção (animais novos, vacinas, ração e outros) [...].

Essa atividade era e continua sendo baseada na utilização de força de trabalho familiar e em pequenas extensões de terra e propriedades diversificadas. Ao pequeno produtor cabe a função de acompanhar o avanço tecnológico da empresa para atingir o padrão de aceite do produto pela indústria para exportação, ou seja, a ideia básica do sistema de integração é que as agroindústrias forneçam toda a tecnologia aos pequenos produtores, ${ }^{5}$ que possuem a tarefa de engordar os animais.

No caso do frango, as indústrias fornecem os pintinhos com padrão genético definido, ração especial, remédios e assistência técnica, enquanto os integrados cuidam das aves até a hora do abate. Desta forma, a indústria não necessita gerar os espaços de criação e de produção da matéria-prima, mas mantém um monopólio de exploração e de controle sobre os trabalhadores familiares. No sistema de integração só permanece quem se associa à indústria ou, ainda, se conseguirem manter os níveis de exigência da produção ditados por elas. Muitas vezes, essa associação ocorre através da dependência de financiamento para a construção de seus aviários. Aqueles que não conseguem, obviamente, são descartados do sistema,

[...] já que não têm para quem vender seus produtos. Os que não conseguem acompanhar o nível de normas e de investimentos exigidos pela indústria são obrigados a abandonar essa atividade produtiva e, muitas vezes, migram para a área urbana para tentar a sobrevivência que no campo não foi possível (Reche, 2008, s/p.).

\section{Cabe lembrar que}

[...] o prejuízo devido a qualquer variação na política econômica, ou uma crise cambial ou ocor-

${ }^{5}$ Nos últimos anos, conforme Fernandes \& Queiroz (2006), "[...] vem surgindo um novo modelo de avicultura integrada, cujas principais características são produtores integrados de porte médio ou grande. Esta nova realidade é para que os integrados tenham maior capacidade de alavancarem financiamento, principalmente para a automação dos aviários". 
rência de peste na criação acabam recaindo sobre o pequeno produtor rural familiar, e não sobre a empresa, já que esta se exime da responsabilidade de compra da matéria-prima em momentos de crise do consumo. (Reche, 2008, s/p.).

Qual é, então, o desenho do Sistema de Integração?

De acordo com o que já foi exposto, o sistema de produção avícola integrada é uma forma de parceria que ocorre entre produtores rurais (neste caso os pequenos avicultores familiares) e as agroindústrias (neste caso a Sadia). Esse sistema se baseia no fornecimento, por parte da agroindústria, dos pintinhos (com um dia), da ração, medicamentos, vacinas, assistência técnica e veterinária ao avicultor que, por sua vez, realiza o trabalho de engordar o pintinho até se tornar frango, devolvendo-o para a agroindústria para o seu abate.

Para que o pequeno produtor e sua família possam realizar essa atividade, eles têm que contar, em sua propriedade, com as instalações necessárias, como a construção do aviário dentro das normas exigidas pela agroindústria, bem como devem arcar com a compra dos equipamentos necessários para o manejo das aves, gastos esses que, muitas vezes, estão vinculados a financiamentos bancários, ou, até mesmo, a financiamentos oferecidos pela própria empresa "parceira”.

O Oeste Catarinense sempre foi conhecido $\stackrel{\infty}{-}$ como uma região com vasta matéria prima, no que tange à criação animal, prioritariamente a suína. Quando os frigoríficos chegaram, já existia uma produção significativa para o processamento industrial, mas essa produção não seguia padrões regulares. Segundo Lusa (2008, p. 55)

[...] foi neste contexto de necessidade constante de matéria-prima com base numa oferta com fluxo contínuo e com procedência garantida, que os frigoríficos instalados na região do Oeste Catarinense, iniciaram 'o processo de extração da produção organizada com base no trabalho familiar', denominado de 'fomento de integração'.

Essa experiência foi iniciada em 1951, no segmento da suinocultura, pelo Frigorífico Con- córdia, que, mais à frente, se tornaria a Sadia e, a partir de 2009, com sua fusão com a Perdigão, passaria a ser conhecida como Brasilfoods. No início da década de 1960, o Frigorífico ampliou a experiência para a avicultura, quando essa prática começava a ser reconhecida como agroindústria, e as pequenas propriedades rurais familiares, que desejavam produzir para além da sua necessidade de subsistência, aderiram ao sistema de integração.

O sistema de integração, portanto, é um modelo de "parceria”, organizado pela própria agroindústria, que inicia a partir de um acordo que integra trabalhadores/produtores rurais familiares e a respectiva empresa, na efetivação da garantia da matéria prima para a produção das mercadorias pela empresa.

Cabe destacar que o contrato que rege o sistema de integração entre as agroindústrias e os fornecedores da matéria prima compreende, por um lado, a compra do frango, ou seja, dos animais "criados" pelos pequenos avicultores familiares rurais, exclusivamente pela empresa contratante, resultando em certa "segurança” aos pequenos produtores. Por outro, obriga os agricultores integrados a seguirem as orientações técnicas, a compra das rações, dos pintinhos, dos medicamentos e das vacinas das "parceiras" agroindustriais (Lusa, 2008, p. 56).

Mas, como se dá essa compra dos frangos dos pequenos produtores familiares rurais pela empresa contratante?

De acordo com Franco et al. (2011, p. 177), ao estudarem alguns contratos do sistema de integração, o valor pago pelo frango baseia-se na quantidade existente em um determinado lote, sendo descontadas as imperfeições físicas, além da mortalidade incidente, considerando-se, ainda, a conversão alimentar. ${ }^{6}$ Ou seja, a remunera-

${ }^{6}$ Segundo Lusa (2008, p. 53), a conversão alimentar se calcula "[...] a partir do registro do peso inicial do animal que adentra na propriedade, é feito cálculo do percentual em peso de carne que ele adquiriu até a data do abate, inserindo neste cálculo do tempo [...]" que o pintinho "[... permaneceu na engorda, o tipo de ração que ingeriu, a quantidade de frangos que morreram [...]" no período, “[...] a qualidade e/ou defeitos dos animais entregues para a agroindústria, entre outros fatores.” Desta primeira conta 
ção ao pequeno produtor toma como base a sua produtividade.

É importante lembrar que, no final do século XX, com o advento do neoliberalismo, o sistema de produção capitalista (tanto urbano, quanto rural) passou por uma reestruturação, trazendo mudanças significativas para o mundo do trabalho, no plano nacional e internacional. Entre as mudanças, está a remuneração por produtividade, que leva ao crescimento da intensificação do quantum de trabalho, bem como da jornada do labor. (Nogueira, 2004). E, acrescentam Hirata e Doaré (1999, p. 10):

[...] assiste-se a uma dupla transformação paradoxal do trabalho, porque ela parece ir em sentido oposto: de um lado, a implicação do sujeito no processo de trabalho e, de outro, a precarização do emprego, com o desenvolvimento de formas flexíveis do trabalho e o crescimento do desemprego. Esse último movimento é grande e globalizado [...]. Paralelamente ao avanço desse processo, assiste-se ao desenvolvimento de outros processos de globalização [...] como as privatizações e o desenvolvimento da subcontratação. ${ }^{7}$

E essa realidade trouxe novas maneiras de organização do trabalho, dentre as quais a ampliação do sistema de integração é exemplo característico, sendo, em grande medida, uma forma de expropriação ${ }^{8}$ e dominação do capital. (Thomaz Jr, 2003). Dessa forma, parece-nos que este sistema de integração torna-se muito vantajoso para a agroindústria, já que - em grande medida, decorrente da reestruturação produtiva - propicia a subcontratação de "trabalhadores” (no caso pequenos avicultores), situação essa

“[...] provêm um coeficiente de 'conversão alimentar', que é utilizado para calcular a produtividade total do lote, segundo o número de frangos que a agroindústria mandou para o avicultor. Do resultado dessa conta ainda serão "[...] descontados os custos de toda matéria-prima que adentra nas propriedades [...]", como "[...] ração, pintinhos de um dia, medicamentos, etc".

${ }^{7}$ Ver também Nogueira, 2004.

${ }^{8}$ Segundo Marx (1988, p. 273), "A expropriação e a expulsão de parte do povo do campo liberam, com os trabalhadores, não apenas seus meios de subsistência e seu material de trabalho para o capital industrial [...]. Antes, a família camponesa produzia e processava os meios de subsistência e as matérias-primas que depois, em sua maior parte, ela mesma consumia. Essas matérias-primas e esses meios de subsistência tornaram-se agora mercadorias;” [...]. própria do modelo toyotista, levando o pequeno produtor rural familiar à lógica do ganho por produtividade.

Em contrapartida, para os avicultores, parece que o único benefício é a garantia da venda da sua produção (embora, eles nunca saibam ao certo o valor que lhes será pago). Lusa lembra que

[...] este é um dos elementos do acordo de "parceria' que tem dupla face para o trabalhador, pois não podendo ele vender sua produção no mercado livre para outra agroindústria a não ser aquela com quem firmou a parceria, fica sujeito ao preço definido pela agroindústria [...] (2008, p. 61).

Essa situação de subordinação e dependência nos permite, portanto, indicar que a divisão sociossexual do trabalho e o sistema de integração dos pequenos avicultores familiares está imbricada às novas formas de organização da produção, principalmente através das "parcerias" na produção da avicultura, favorecendo, em grande medida, a intensificação da precarização do(a) trabalhador(a) rural.

\section{A PRECARIZAÇÃO NO PROCESSO DE TRABALHO NO SISTEMA DE INTEGRAÇÃO}

O cotidiano de trabalho no sistema de integração é retratado com riqueza de detalhes por alguns de nossos entrevistados. Nos relatos, eles revelam como o trabalho é feito, as dificuldades, quem trabalha, entre outras tantas questões que compõem o mundo produtivo. Quando se questiona por quem o trabalho é realizado, a resposta mais frequente é que o trabalho é feito pela família, conforme podemos exemplificar com o depoimento ${ }^{9}$ de Joana:

\footnotetext{
${ }^{9}$ Todos os depoimentos que seguem são provenientes das entrevistas dadas à pesquisadora Edivane de Jesus (2010) e constam na íntegra em sua dissertação de mestrado com o título "O Sistema de Integração na Produção de Aves no Oeste Catarinense: Análise sobre o processo de trabalho e a relação contratual entre a empresa Sadia e avicultores", sob a orientação da Prof ${ }^{a}$ Dr $^{a}$ Claudia Mazzei Nogueira. Cabe destacar, ainda, que os nomes dos depoentes são
} todos fictícios. 
Sim, toda a família. À menina, nós demos um secador de cabelo pra limpar, porque [...] não dá pra entrar com as mãos pra tirar, daí com o secador de cabelo ela vai todas as tardes, limpa que entra aquela maravilha, tem que limpar tudo, daí vai sempre ela [...] nós dividimos as tarefas. [...] Por exemplo, a parte mais pesada, dá ração, tirar a ração molhada vamos nós. [...]. Todos trabalham, até o filho, que ele tá lá na roça, mas hoje de manhã ele também ajudou no aviário (Joana).

Esses depoimentos parecem corroborar com a análise de Graziano da Silva (1982, p. 36), referente à pequena propriedade:

[...] a família é a unidade básica de produção, e o assalariamento temporário entra apenas como complemento nos períodos de maior serviço, ou seja, eventualmente. Esse é o ponto fundamental no que diz respeito à mão-de-obra ocupada na agricultura brasileira: presença marcante do trabalho familiar. A sua participação é inversamente proporcional ao tamanho dos imóveis; ou seja, quanto menor a propriedade em termos de área e/ou valor da produção, maior é a importância do trabalho familiar.

Apenas dois dos dez integrados entrevistados têm empregados que auxiliam nos cuidados diários com o aviário. Um deles menciona que tem empregados em função da idade avançada, já que quem mora e trabalha na propriedade são somente ele e a esposa. Outro, porque é sozinho no trabalho e mantém, paralela à integração, outra atividade e por isso não dá conta das duas coisas. Sobre o pagamento destes trabalhadores, observa-se que também existe uma relação de precarização. Ao responderem à pergunta: como paga os empregados, obtivemos os seguintes depoimentos:

O que sobra. Que nem esse lote que a mulher falou, não deu pra pagar o empregado. Eles fazem a conta e é o avicultor que tem que trabalhar. Só que quem não tem condições de cuidar tem que pagar outro, que a gente já está com idade avançada. (Avelino).

[...] pra pagar o tratador, se ele ganhar vinte por cento, são quinhentos reais pra ele trabalhar sessenta dias e ficá mais quarenta parado, não tem peão que aguente. Não tem mais mão-de-obra pra trabalhar nos aviários, não existe, ninguém mais que quer. [...] peão tu não arruma, ou se tu arruma é de má qualidade, porque um cara que se preza não vai fazer um serviço desse, porque a expectativa é terrível. Só quem não tem outra coisa, que de repente, não tem onde morar, ganha uma casa e ganha luz e certo, até ele dá uma equilibrada pra saltá em outra coisa melhor. A verdade é essa, pra dizê que vai fica ali pra ganhá dinheiro, não fica, eu acho que se tu entrevistar o pessoal ai e dizer que tem peão há mais de um ano, dois anos, tu vai acha aí, pode ter certeza que o proprietário deu outra saída pro peão. Tem casos vamos dizê assim, dele cuidá da vaca de leite junto entendeu pra podê defendê, mas só do aviário tratador nenhum vive, não tem como viver. (José)

Nos dois casos acima relatados, não há mais filhos vivendo na propriedade e, logo, existe uma carência natural de força de trabalho. Isto retrata o êxodo que vem ocorrendo no campo. Aliás, essa é uma grande preocupação na produção integrada, e aparece tanto na fala dos produtores como na do membro da Federação dos Trabalhadores na Agricultura Familiar - FETRAF que entrevistamos, pois parte significativa da garantia na continuidade dessa atividade está na perpetuação dos produtores familiares rurais.

Na percepção do movimento sindical, o modelo de integração vem gerando vários problemas no Oeste Catarinense, sendo que entre eles está a sucessão nas propriedades.

A questão do sistema de integração, principalmente de aves aqui no Oeste Catarinense não é diferente, o sistema de produção está chegando no limite da sua existência, porque não está conseguindo fazer sucessão nas propriedades onde os avicultores têm as suas unidades, suas produções, suas granjas. Está empobrecendo muito a agricultura, o agricultor, o avicultor integrado, ele não recebe um valor justo pela sua produção e está causando uma série de problemas, inclusive de saúde, de trabalho, de lesões nos próprios avicultores pela quantidade de esforço que tem que fazer nesse processo. Então é um modelo de integração que está com sérios riscos de sua continuidade pensando em 10/ 15 anos. Esta é a avaliação que a gente tem (Fernando, Membro Fetraf-Sul ${ }^{10}$ ).

${ }^{10}$ Federação dos Trabalhadores na Agricultura Familiar da Região Sul do Brasil está organizada em 22 microrregiões, congregando 93 Sindicatos de Trabalhadores Rurais, Sindicatos de Trabalhadores na Agricultura Familiar, Associação Sulinense da Agricultura Familiar, Associação dos Pecuaristas e Agricultores Familiares de. Alegrete/RG e Associação dos Sindicatos dos Trabalhadores da Agricultura Familiar em toda a Região Sul. Com sindicatos regionais fortes, a Fetraf-Sul/CUT abrange mais de 288 municípios no Paraná, Santa Catarina e Rio Grande do Sul." Disponível em: http://www.fetrafsul.org.br/ index.php?option=com_content\&view=article\&id $=51 \& I t e m i d=114$ Acesso 08/11/2010. 
No mesmo viés, observamos que a maioria dos entrevistados está há mais de duas décadas na produção integrada. Outros há mais de 30 anos, sendo que muitos optaram por dar continuidade à atividade que os pais haviam iniciado, conforme sinaliza a fala dos produtores João e Miguel:

Na verdade, eu comecei na integração junto com o meu pai, depois foi que assumi sozinho. $\mathrm{Na}$ época a Empresa procurou o pai e ofereceu. Naquele tempo era uma boa, dava dinheiro, hoje em dia está bem diferente. (João)

Eu já comecei com o meu pai que foi quase um dos primeiros integrados da Sadia. Comecei com meus quinze, dezesseis anos, sempre trabalhei na avicultura. Depois surgiu pra mim, depois que eu casei, foi ele que comprou, esse aviário já era, tava desativado, a gente comprou, fomos pegar na Sadia. (Miguel)

Em contrapartida, encontramos, em outras falas de avicultores familiares, nas quais foi possível perceber como o campo e a produção integrada, na atualidade, não são atrativos aos filhos, como foram no passado para os produtores da geração que entrevistamos. Este processo é consequência de uma soma de fatores, já mencionados, e tem como principal força motriz a precarização das condições de vida e trabalho dos produtores. A situação que vêm vivenciando os pequenos produtores familiares na atividade põe em risco o modelo de integração tal qual ele se apresenta hoje. Vejamos os depoimentos a seguir, que acentuam o problema geracional acima indicado:

Então é uma coisa que pelo pouco que dá, mas até que a gente conseguir trabalhar vai. Mas eu, o meu filho ele tem dezessete anos, então ele diz que ele vai estudar, ele não vai ficar e cuidar do aviário futuramente. Então até que eu e meu marido a gente pode cuidar o aviário a gente cuida e depois... não sei até quando (Inês).

Tenho dois [filhos], mas nunca trabalharam não. Não, eles não querem não. Se eu disser pra eles, ó vou deixá pra vocês isso, eles não querem aí. Já começaram desde cedo a trabalhar fora. Aí fiquei sozinho com o trabalho (Miguel).

A precarização das condições de trabalho ocorre, portanto, em diferentes vertentes, como as de gênero, geração, subassalariamento etc. As exigências se intensificam, a cada dia, sendo que uma das questões que mais chamou nossa atenção nas entrevistas realizadas foi a extenuante jornada de trabalho a que os produtores integrados estão subjugados.

Todos os produtores, ao discorrerem sobre esse tema, mencionaram que a responsabilidade pelo cuidado das aves os acompanha vinte e quatro horas por dia, sete dias na semana, durante todo o tempo em que os animais estão alojados. Ao considerarmos como trabalhadores que vivenciam uma situação de assalariamento disfarçada, observamos que, talvez nem no auge da revolução industrial, quando trabalhadores tinham jornadas de trabalho que excediam o limite das forças humanas, isso ocorria com tanta intensidade. O trabalhador ainda possuía um tempo para o descanso, para repor suas energias e, deste modo, restabelecer sua capacidade produtiva.

Olha, de trabalho mesmo, você tem que ficar vinte e quatro horas atento, não é de trabalho braçal as vinte e quatro horas, mas, tem que ficar o tempo inteiro, você tem que ficar, tá atento ali no serviço. (Miguel)

Essa realidade nos remete a Antunes (1999, p. 174-175), que desenvolve a ideia de uma vida dotada de sentido dentro e fora do trabalho, uma vez que segundo o autor “[...] pode-se articular a ação contra o controle opressivo do capital no tempo de trabalho e contra o controle opressivo do capital no tempo de vida [...]", e complementa: "[...] em alguma medida, a esfera fora do trabalho está maculada pela desefetivação que se dá no interior da vida laborativa [...]". Ou seja, para os pequenos avicultores familiares não existe praticamente tempo livre:

O aviário se vai olhar dentro dos dias, tem dias que vai dar mais serviço tem dias que vai dar menos [...] o único problema do aviário é que feriado, domingo, sábado você não tem. Quando tem os bichos, os frangos dentro do aviário isso aí é praticamente direto. De noite também, às vezes meia noite você tem que levantar fazer fogo, principalmente agora no inverno tu vai ter que tá ali. Na verdade é vinte e quatro horas. O avicultor que hoje tem aviário de frango eu digo que é vinte e quatro horas. É claro que não vai traba- 
lhar vinte e quatro horas, mas tem que ficar vinte e quatro horas, porque se você está dormindo, duas da madrugada, o tempo veio com a chuva ou é frio você vai ter que levantar e atender, até porque se você não fazer isso o teu resultado no final vai lá prá baixo, aí sim, já tá pouco cuidando bem, calcule não cuidando, aí vai ser pior, mas é complicado. (Nilson)

Sim. Não tem hora, a hora que precisa tu tem que tá lá e é direto, se é de dia, se é de noite tu tem que levantá, se for pequeno fazer o fogo, se precisa carregá, tu tem que levantar de noite, se vem ração tu tem que levantá de noite, é vinte e quatro horas por dia, a ração também. Se tu pede a ração, se te chegar lá meia noite, uma hora, duas horas, tu tem que levantá e ir lá atender. (Maria)

É de manhã até de noite. Ontem chegou os pintinhos, nós estamos com pintinho pequeno. Então chegou os pintinho ontem à noite e daí a gente alojou, ajeitou a cama e vai e daí depois tem que levantar fazer fogo de noite a cada duas, três horas e de manhã é também a cada duas, três horas tem que entrar no aviário fazer fogo, botar ração, mexer ração e depois quando eles crescem é todo o dia, cada pouquinho tu tem que ir no aviário, eu não sei te dizer quantas horas. (Inês)

Na maioria das situações, a família se reveza e divide a responsabilidade. Assim, não é apenas o produtor direto, aquele que assina o contrato, que assume o encargo, mas, junto com ele, todos os membros do grupo familiar. A empresa não toma para si apenas o trabalho do dito "parceiro", mas de seus filhos, esposa, etc.

Esse alargamento da apropriação do trabalho nos remete à Marx (1971, p. 449-450),
Embora, a análise de Marx (1971) esteja se referindo ao espaço da produção industrial, do trabalho assalariado, podemos afirmar que, no sistema de integração da Sadia estão presentes fortes traços da exploração do capital produtivo em geral.

O sistema de "parceria" que contempla o sistema de integração resulta em uma relação extremamente vantajosa para a empresa, tendo em vista que o contrato de parceria é com um só avicultor, mas, de fato, são vários trabalhadores/as, de certa forma "gratuitos", à sua disposição, conforme podemos constatar nas respostas a seguir.

Tem dias que em média seis horas por dia, mais ou menos. Mas aí a cada duas horas você tem que tá no aviário de noite, aí tem todas as máquinas grande, tu tem que trocar, duas horas vou eu, as quatro vai o outro e depois outro. É direto. Aî tem o aquecedor, as máquinas de quatorze mil cada fogão, que nós investimos e ele é automático, ele se liga e se desliga a temperatura que tu botô e se coloco com trinta e dois grau, ele é automático, com trinta ele se liga, com trinta e dois ele se desliga, não adianta. Só que a preocupação é vinte e quatro horas porque se nós perder uma hora, se não tem ninguém em casa, se largar o aviário o lote já foi, porque se você não cuidou, você já perdeu. (Pedro)

Sabiamente, a pequena avicultora menciona a sua opinião em relação ao sistema de integração, antes de explicitar o envolvimento familiar no manejo das aves.

É uma cadeia de portas abertas, é uma prisão de portas abertas, eu acho que é uma prisão de portas abertas, [...]. Tu quer ganhar bem tu tem que tá lá dentro, tem que ta lá de hora em hora, de pequeno hora em hora, tem que ir [...] vai e volta. (Joana)

É, [...] parece uma cadeia, não tem um fim de semana, só quanto tiver intervalo dos lote, daí você pode sair. (Pedro)

Joana continua seu relato, agora, trazendo detalhes do cotidiano de trabalho na atividade do manejo, explicitando o envolvimento da família e como organizam a rotina e o processo de trabalho de acordo com as possibilidades de cada membro do grupo:

Olha, deixa eu contar. O meu filho ele saiu de noite, então ele chegou à meia noite, ele foi e botô 
lenha na máquina. Antes de dormir, nove horas eu já tinha subido e enchido a máquina de lenha. Daí, à meia noite, ele veio, colocou lenha daí ele foi dormir. Duas horas da manhã ele levantou e foi novamente colocar lenha na máquina. Cinco e meia da manhã eu levantei e fui colocar, porque só ele, só um pegar no pesado não dá né. O meu esposo ele não vai porque ele não tem muita saúde você sabe, ele não tem muita saúde por isso ele não vai de noite botá lenha na máquina e levantar da cama. Até os vinte dias é bastante puxado, mas depois também não é esse grande, grande trabalho, mas até os vinte dias, mexe a cama, depois é só tu ficar de olho. A gente tem tipo um motorzinho que vai só com um, vai indo, vai mexendo com a ração todo dia e ração não precisa muito, a gente recolhe os morto, conta quantos, mas, depois dos vinte dias não é muito serviço, mas até os vinte dias minha nossa. (Joana)

Nesta direção, retomando as reflexões de Graziano da Silva (1980), a pequena produção é importante à economia por gerar uma parcela considerável de produção agrícola. De outro lado a “[...] sua existência também significa um alto grau de exploração da força de trabalho [...]”, isto porque os trabalhadores têm a necessidade de intensificar e aumentar a jornada no sentido de obter a subsistência. Deste modo, a jornada de trabalho não precisa nem ao menos ser fixada, muitas vezes a necessidade acaba por fixar a jornada.

Conforme Marx (1983, p. 206):

O prolongamento da jornada de trabalho além dos limites do dia natural por noite a dentro serve apenas de paliativo, apenas mitiga a sede vampiresca por sangue vivo do trabalho. Apropriar-se de trabalho durante todas às 24 horas do dia é, por conseguinte, o impulso imanente da produção capitalista.

Neste sentido, o depoimento que segue, para nosso espanto, sinaliza que a jornada de trabalho extenuante não está apenas encoberta na relação de trabalho com vistas ao processo produtivo. De acordo com entrevistado, a empresa exige, claramente, esta disponibilidade do produtor:

É vinte e quatro horas. A empresa, eles exigem que você fique vinte e três horas atento esperando, porque a ração pode vir a qualquer hora do dia ou da noite, é vinte três horas por dia. Mas na verdade tu tem que ficar vinte e quatro horas porque, a ração, eles param uma hora lá na Empresa, das onze e começam a meia noite. Então das onze à meia noite eles não têm expediente, mas o caminhão que carregou às onze, ele tá na estrada. Então na realidade é vinte e quatro horas por dia. Que nem aconteceu aqui com nós, de nós tá num velório [...]. Daí tu liga lá [...] antes, pedindo que não me mandassem a ração, ele disse que não podiam interromper a distribuição. - Eu vou num velório hoje à noite, eu não vou tá em casa. Tem que deixar alguém responsável, e o rapaz peão foi dormir. Olha, de trabalho mesmo, você tem que ficar vinte e quatro horas atento, não é de trabalho braçal às vinte e quatro horas, mas, tem que ficar o tempo inteiro, você tem que ficá, está atento ali no serviço. (Avelino)

A impessoalidade da relação é tamanha que não importa que tipo de situação que o avicultor esteja vivenciando, os cuidados com a produção e a vigília não podem ser interrompidos. Considerando as leis trabalhistas brasileiras, caso a empresa ainda mantivesse o modelo de produção que antecedeu à integração, seriam necessários três funcionários em três turnos de oito horas cada, para atender à demanda do cuidado das aves. Assim, seriam três contratos de trabalho, três salários e direitos trabalhistas pertinentes à legislação. Neste sentido, voltamos a identificar que a situação que vivenciam os produtores mistura o que há de mais arcaico, herança do nosso passado rural escravista, com o que há de mais "moderno" em termos de processo produtivo, como a mecanização e as metas de produtividade.

E esta relação nos remete à excelente crítica da razão dualista feita por Chico de Oliveira (s/d, p. 32):

Essa combinação de desigualdades não é original; em qualquer câmbio de sistemas ou de ciclos, ela é antes uma presença constante. A originalidade consistiria talvez em dizer-se que - sem abusar do gosto pelo paradoxo - a expansão do capitalismo no Brasil se dá introduzindo relações novas no arcaico é reproduzindo relações arcaicas no novo, um modo de compatibilizar a acumulação global, em que a introdução das relações novas no arcaico libera força de trabalho que suporta a acumulação industrial-urbana e em que a reprodução de relações arcaicas no novo preserva o potencial de acumulação liberado exclusivamente para os fins de expansão do próprio novo.

Neste emaranhado, o produtor perde por completo a autonomia, não apenas do seu proces- 
so de trabalho, mas as próprias rédeas da sua vida. Quando nos relataram a jornada de trabalho a que estavam submetidos, o nosso primeiro impulso foi perguntar sobre a parte da vida que não é trabalho, o lazer, quando e como se divertiam, que estratégias usavam frente à realidade vivenciada.

Com relação à possibilidade de lazer, os depoimentos dos produtores foram os seguintes:

Ah, mas é difícil, é todo o dia a mesma coisa. Talvez tem uma festa na comunidade você vai. Você vai almoçar, daqui uma hora e meia, duas horas você tem que voltar, você tem que estar em casa. Se divertir mesmo é difícil. (Miguel)

Se tem uma festa na comunidade você não pode ir. Você até vai, mas tem que voltar, tem sempre um compromisso. Viajar com a mulher não pode, ou viaja um, ou viaja outro. Para quem tem empregado, pode deixar tratado com ele, mas é assim você tem que ficar sempre de olho, tu é meio escravo desses bichos. (Avelino)

Não, não é que a gente não saia, a gente sai, mas quando sai, por exemplo, saio eu e a mulher fica ou o piá. Tem que ficar meio por perto, até porque é aquela questão você não sabe o tempo o que vai acontecer, como vai estar, então sempre um tem que ficar. Dificilmente você sai o dia inteiro e deixa o aviário sozinho, isso é difícil, não existe, nem tem como não. (Nilson)

Não, por causo que tu tem que ficar cuidando, se estoura uma manga de água, se estoura um cano de ração, aí é aquela coisa, aquele serviço, tu tem que tá presente, é um compromisso. (Maria)

Às vezes consegue sair. Se tiver aves ali é você sair no máximo de duas ou três horas que você pode ficar longe, daí você tem que ter alguém perto de casa. Livre mesmo você vai ficar a partir da hora que você não tiver nada alojado daí fica mais fácil pra sair com a família, mas é uma atividade que requer tempo disponível e sempre alguém aí perto. (João)

É difícil, não tem como. Porque como é só nós dois praticamente, então ocupa todo o tempo da gente. Então o aviário é uma coisa que você não pode abandonar, sair e abandonar [...]. Então é um compromisso, a gente não tem esse tempo de sair, a gente sai, mas daí já tem que voltar, ou um sai o outro tem que ficar. Então não é fácil aqui. Olha, agora faz uns dois ou três anos que praticamente a gente tá só em casa. [...] uma vez quando saía o lote, no verão praticamente a gente reunia uma turma e a gente ia pra praia ou ia num campo, ficava dois, três dias, essa é a diversão da gente porque todo o dia é ali na lida, fim de semana também. (Inês)

Observa-se, assim, que os momentos de descontração e lazer, quando existem, não podem ser compartilhados por toda a família. Esta lógica afeta, claramente, a vida e a dinâmica familiar, acabando por alterar sua cultura, seus hábitos, estabelecidos por gerações. A produção passa a controlar e organizar as demais esferas da vida. O que também é um traço marcante da produção capitalista, conforme acentuou Marx (1988, p. 202), em O Capital:

De quanto é o tempo durante o qual o capital pode consumir a força de trabalho cujo valor diário ele paga? Por quanto tempo pode ser prolongada a jornada de Trabalho além do tempo de trabalho necessário à reprodução dessa mesma força de trabalho? A essas perguntas, viu-se que o capital responde: a jornada de trabalho compreende às 24 horas completas, depois de descontar as poucas horas de descanso, sem as quais a força de trabalho fica totalmente impossibilitada de realizar novamente sua tarefa. Entende-se por si, desde logo, que o trabalhador, durante toda a sua existência nada mais é que força de trabalho e que, por isso, todo seu tempo disponível é por natureza e por direito tempo de trabalho, portanto, pertencente a autovalorização do capital. Tempo para educação humana, para o desenvolvimento intelectual, para o preenchimento de funções sociais, para o convívio social, para o jogo livre das forças vitais físicas e espirituais, mesmo o tempo livre de domingo - e mesmo no país do sábado santificado - pura futilidade!

\section{E complementa:}

Mas, em seu impulso cego, desmedido, em sua voracidade por mais-trabalho, o capital atropela não apenas os limites máximos morais, mas também os puramente físicos da jornada de trabalho. Usurpa o tempo de crescimento, o desenvolvimento e a manutenção sadia do corpo. Rouba o tempo necessário para o consumo de ar puro e luz solar. Escamoteia tempo destinado às refeições para incorporá-lo onde possível ao próprio processo de produção, suprindo o trabalhador, enquanto mero meio de produção, de alimentos, como a caldeira de carvão e a maquinaria de graxa ou óleo. Reduz o sono saudável para concentração, renovação e restauração da força vital a tantas horas de torpor quanto à reanimação de um organismo absolutamente esgotado torna indispensáveis. Em vez da conservação normal da força de trabalho determinar aqui o limite da jornada de trabalho, é, ao contrário, o maior dispêndio possível diário da força de trabalho que determina, por mais penoso e doentiamente violento, o limite do tempo de descanso do trabalhador. O capital não se importa com a duração 
de vida da força de trabalho. O que interessa a ele, pura e simplesmente, é um maximum de força de trabalho que em uma jornada de trabalho poderá ser feita fluir. Atinge esse objetivo encurtando a duração da força de trabalho, como um agricultor ganancioso que consegue aumentar o rendimento do solo por meio do saqueio da fertilidade do solo. (Marx, 1988, p. 202 e 203).

No sentido dado por Marx (1988), todos os elementos que os produtores oferecem sobre sua jornada de trabalho e rotina no processo produtivo nos fazem indagar sobre a saúde desses avicultores. Muito embora esta não fosse uma questão central do nosso estudo, trouxemos alguns elementos que surgiram nas respostas dos entrevistados, que dizem respeito às implicações (imediatas ou futuras) dessa atividade nas condições de saúde dos que trabalham na produção.

Miguel, um dos entrevistados, no momento afastado da atividade em função de complicações na saúde e recebendo auxílio doença do INSS, menciona:

Estou com um problema sério de coluna. Eu tive que fazer duas cirurgias de coluna, e até não me recuperar estou parado encostado, recebendo do INSS. Com certeza é da atividade, praticamente trabalhei sempre, sempre com isso, com aviário. Faz esforço, trabalha bastante abaixado, sempre numa posição, isso que força a coluna. (Miguel)

Já Pedro, outro entrevistado, faz menção a problema respiratório, relacionando-o com a atividade do manejo e sinaliza posição da empresa, totalmente alheia a qualquer problema que o trabalhador venha a desenvolver em decorrência da atividade.

Eu sou alérgico e o aviário tá fechado aquele gás da cama, já fez o calor, e aquele gás, dá febre e aí fui lá, peguei uma médica particular e ela disse que é um pouquinho de alergia, mas não é muito, fiz todos os exames. Para empresa não importa se você gastou ou não gastou com a saúde. Quando o aviário tá aberto aí a gente pode ir lá e trabalhar, agora se tiver fechado, não fica bem. A ração também carrega nas costas, a coluna que todo mundo fica com problema. (Pedro)

Outros entrevistados, apesar de mencionarem que, no momento, não estão com problemas de saúde, conseguem relacionar o trabalho dentro do aviário com possíveis e futuros agravos na condição de saúde. Neste sentido, elencam fatores que podem vir a contribuir com este processo:

Olha, eu acredito que sim, porque até a poeira, mas o que eu acho que vai mais futuramente prejudicar a gente é a troca de temperatura, você tá hoje , que nem eu falei, você tá hoje no inverno principalmente você sai, você tá dormindo ou mesmo que você tenha a máquina automática lá, você sai numa temperatura de oito graus ou dez graus você chegar entrar no aviário tá vinte e oito, trinta graus, aí você vai entrar lá, você vai ficar quinze, vinte minutos dentro do aviário de trinta graus, você vai sair aqui pra fora vai tá abaixo de oito graus. Então eu acredito que quem cuida de um aviário ali vinte, trinta anos talvez não, tomara que não, mas eu acho que alguma coisa deve acontecer, porque tem amônia, gases, a própria poeira, é complicado. (Nilson)

Uma coisa, que no inverno quando o frango é pequeno, então você entra no aviário e sai muito. A temperatura lá dentro quase trinta graus e sai pra fora frio. Então isso eu acho que não é legal, tem uma época que eu acho que não vai dar certo. Geralmente no inverno quando acontece isso, que tem o frango pequeno, praticamente todos os lotes no inverno, a gente pega resfriado, pega tosse, essas coisas, então eu acho que talvez no futuro sempre entrando e saindo no aviário, eu não sei, eu não posso dizer que sim, mas eu acho que pode trazer problema. (Inês)

Eu acho que toda a atividade expõe. Principalmente o aviário, pela concentração de gás de cama que é o complicado, por mais que você vai dizer, não, mas é ventilado, tem ventilação, mas se tu pega um dia de frio vai ventila o quê? Se vai jogá ar pra dentro tu mata tudo de frio, tu tem que aguentá o baque lá dentro, não tem conversa, tu tem que fazer a temperatura subir, tu tem que deixar vinte oito, trinta graus dentro do aviário, ai tu vai ventilar como? (José)

Pode. Porque vou te dizer uma coisa, esses dias, até o dia que chegou era frio, era bem friozinho, foi numa segunda feira, acho que faz quinze dias amanhã, tava trinta e dois graus lá dentro. Eu saí de lá, tirei a blusa, eu tava suada lá dentro e aqui fora tava doze graus. Lá dentro trinta e dois, eu vim aqui fora doze graus. Lá dentro tem um termômetro que é direto no painel, você vê a temperatura, trinta e dois graus quando deixei lá, tem que ser assim, e depois quando que eu saí aqui fora o termômetro aqui doze graus, então como é quê?. E de noite, tu levanta da cama quentinho, tu sai daqui, tu vai lá, tu chega lá, eu boto uma manta no pescoço, me agasalho bem e vou, mas eu entro lá, eu tenho que tirar tudo, depois sai ali fora eu tô me vestindo de novo porque a queda é muito grande. Eu digo que pode, mas graças 
a Deus a gente se cuida, toma remédio. Eu tenho saúde, mas meu marido não muito, eu graças a Deus eu tô bem. Ah tem dias que eu me entrego também, já a idade começa pegar um pouco também, mas agora eu não posso me queixar, vai indo, eu tive problema de saúde, mas agora tô boa. (Joana)

A empresa, entretanto, parece não demonstrar nenhuma preocupação com a saúde dos produtores. Questionamos os entrevistados se existia alguma ação, por parte da integradora, com vistas à proteção/recuperação da saúde do integrado, como, por exemplo, se a empresa fornecia equipamento de proteção, passava instruções sobre manejo adequado. Os entrevistados mencionaram que a empresa não disponibiliza equipamentos de proteção e que raramente recebem orientações com relação a qualquer prevenção relativa à saúde. Nesta direção, um dos entrevistados comentou que, na sua percepção, a empresa deveria ter responsabilidade na prevenção e recuperação da saúde dos produtores. Na sua simplicidade, põe em foco uma questão essencial: afinal, o que importa, é só o bem estar do animal ou do trabalhador, do ser humano?

Eu penso que eles deviam dar tudo pra gente, médico, dentista alguma coisa a mais, ajudar os avicultor direto, nessa parte. Então eles aqui já vêm com várias exigências pra gente por causa do bem estar do animal. Mas, assim, a gente conversando: Tá, o bem estar do animal, mas e o nosso? Esse é o problema. Eu converso bastante, falo direto com o técnico. Quando diz bem estar do animal quer dizer o seguinte, bem tratado, conforto, ar condicionado tudo. Não pode estragar uma perna, o frango é assim. (Pedro)

Pelo que vimos, a vida da ave é mais cara à empresa do que a do produtor e sua família Na relação capitalista de produção, na qual os produtores estão inseridos, ainda que seu trabalho seja uma mercadoria inacabada, uma matéria prima, uma vez que ainda vai passar pelo processo de industrialização que viabiliza sua comercialização, o que importa à empresa é a mercadoria e não quem a produz. Para o sistema capitalista, e em particular para o sistema de integração estudado, os pequenos produtores rurais só valem algo enquanto imprescindíveis para a produção da mercadoria, no caso, as aves. E as condições de vida e trabalho, como pudemos apresentar, são sempre precarizadas em muitos de seus aspectos cotidianos.

\section{CONSIDERAÇÕES FINAIS}

Após a realização das reflexões acima, podemos afirmar que o sistema de integração surge da necessidade de expansão e "modernização" da produção agroindustrial, que necessitava de vasta matéria-prima para o abastecimento das agroindústrias.

Este sistema tem sua base legal na relação de parceria, tratando-se, de certa forma, de um tipo de trabalho a domicílio, uma vez que os pequenos produtores estudados, embora detenham parte significativa dos meios de produção, em verdade encontram-se subsumidos à empresa capitalista que, em grande medida, controla a sua vida, sugerindo uma acentuada precarização de todos (as) aqueles (as) que atuam nessa atividade avicultora.

Marx, em O Capital, nos dá ótimas pistas ao analisar o período da manufatura, que caracteriza a passagem do artesanato para a grande indústria. Durante essa fase, o detentor do capital fornecia a matéria-bruta ao ainda artesão que, domiciliarmente, em seu microcosmo, muitas vezes com a ajuda da sua família, transformava aquela matéria-prima em mercadoria, sendo parte integrante do processo produtivo. No caso da avicultura vinculada ao sistema de integração, podemos identificar muitos elementos de similitudes. Por exemplo, as aves de um dia são fornecidas pela "parceira" integradora e os pequenos avicultores familiares são responsáveis pelo manejo, engordando as pequenas aves até se tornarem frangos, com o peso ideal para o abate. A empresa capitalista, por sua vez, recolhe a mercadoria/matéria prima, agora mais elaborada, e realiza o abate, terminando o processo de produção em sua planta industrial, resultando na mercadoria final. Isso indica, em grande 
medida, que os pequenos produtores familiares rurais, de fato, fazem parte integrante da cadeia produtiva, porém, à margem da legislação trabalhista e sem proteção social.

Os avicultores encontram-se submetidos a jornadas extenuantes de trabalho, não tendo, praticamente, tempo para as suas relações familiares, principalmente aquelas voltadas para o convívio lúdico, informal e social, o que traz consequências profundas em sua saúde física e mental. Portanto, podemos afirmar que o avicultor familiar, em verdade, tem parte significativa de seu tempo de trabalho sob o comando do capital, como ocorre com o conjunto da força de trabalho assalariada.

Cabe lembrar que, com o processo de reestruturação produtiva, essa situação se intensificou, pois novas exigências surgem para os pequenos produtores rurais integrados, entre elas a implantação de equipamentos tecnológicos mais avançados nos aviários, bem como as transformações no manejo e cuidados necessários para com os lotes de frangos, aumentando a jornada e a intensificação do trabalho, como pudemos indicar nos depoimentos colhidos.

Essa realidade, encontrada nas pequenas propriedades rurais familiares vinculadas ao sistema de integração, permite afirmar que a precarização do trabalho realizado na avicultura, não só se encontra presente como, em certo sentido, está se acentuando. Por exemplo, a necessidade da "atenção direta", ${ }^{11}$ uma exigência do sistema de integração de aves, que segundo Lusa (2008, p. 144), ao se referir ao trabalho rural, afirmou que, antigamente, antes da implantação da "atenção direta", desde as cinco horas da manhã, já se iniciava a jornada de trabalho, que se encerrava antes das vinte horas, "[...] quando a família se retirava para a casa a fim de tomar banho, jantar e descansar para repor as forças despendidas durante o dia. Com o surgimento desta nova forma de trabalho ('aten-

11 "Atenção direta" é o tempo necessário dispensado para o uidado com o aviário. Quanto menor for a implantação e o padrão de equipamentos tecnológicos no aviário, maior é o dispêndio de tempo no manejo das aves. (Lusa, 2008, p. 47). ção direta'), as famílias [...]” não encerram suas tarefas laborais "[...] ao entrarem em casa à noite para jantar e descansar, pois lhes é exigido continuar as atividades no período noturno, interrompendo geralmente três vezes seu sono para fazer a vistoria [...]" no aviário.

Para além de uma jornada de trabalho extenuante, os pequenos produtores percebem pelo seu trabalho um valor equivalente muito baixo, conforme podemos constatar no depoimento que se segue:

[...] pra te ser bem sincero faz três meses que eu tô com o aviário sem receber, sem ver dinheiro vamos dizer e com dívida do aviário. A situação tá aí, e ainda os lotes caíram, os valor um absurdo. Esses dias eu até vi uma entrevista, disseram que dava cinco mil a média, mas da onde que tiraram essa conta aí? Quem que tá pagando isso aí? A minha média aqui, o aviário quando dá seguro é dois mil e pouco não paga o custo, não paga o custo de produção, ou se bota custo de produção o aviário não paga. O seguro que a empresa paga hoje pra nós, não paga custo de produção nunca. Hoje um custo de produção pra fazer um aviário, seja qualquer integração que for é cinco mil. Setecentos pau eu gastei o mês passado de luz, num mês, pra tu chega no final do lote que nem de cinqüenta metros que eu tenho aqui, reformei cinqüenta e cinqüenta vou reformar agora, é dois mil e duzentos reais. Então nós estamos trabalhando pelo mínimo, nós estamos pagando pra trabalhar [...]. Aí tu fica quarenta dias parado, mais cinqüenta pra tu alojar, pra ter pintinho, vai noventa dias pra tu vê dinheiro. (José)

Podemos perceber que os pequenos avicultores familiares estão passando por sérias dificuldades, além de presenciarem um processo de aumento da exploração e precarização de suas condições de trabalho, sendo frequentemente forçados a desenvolverem outras atividades laborativas, concomitantemente com a do sistema de integração, para garantir a sua subsistência e da família, ou, ainda, para honrar as dívidas contraídas para a modernização de seu aviário, exigência essa própria da relação de integração.

Por conta deste cenário desenhado, cremos que o modelo de integração, seja por parte da Sadia ou das demais agroindústrias da região, num futuro próximo, para além dos problemas enfrentados pelos pequenos avicultores familiares, tenderá a buscar "parcerias", preferencial- 
mente, com as médias e grandes propriedades rurais, que, embora sejam também estruturadas familiarmente, empregam força adicional de trabalho assalariado, podendo, por isso, responder mais rápido e adequadamente às exigências postas pelo sistema de integração, propiciando, desse modo, uma maior acumulação de capital por ambas as partes: integrados/integradoras.

Outro modo do qual as agroindústrias poderão se utilizar para garantir seu fortalecimento no mercado - considerando a capacidade que o capital tem de se metamorfosear e reorganizar suas bases de modo a atender seus objetivos de extração de mais valia e acumulação - será ampliando a tendência à monopolização. Aliás, a fusão entre a Sadia e a Perdigão, criando a Brasilfoods, é um claro exemplo da tendência, já apontada por Marx, de que o capital tem de centralizar-se para se fortalecer. E é possível que esse processo de crescente monopolização da agroindústria acarrete transformações no sistema de integração, beneficiando as médias e grandes propriedades familiares rurais em detrimento das pequenas.

Segundo Marx, a centralização reforça e acelera os efeitos da acumulação, podendo, entretanto, ocorrer de maneiras distintas, sendo que, no caso em questão, trata-se da fusão de capitais já constituídos. Por ser um movimento natural deste modo de produção,

\begin{abstract}
[...] a centralização complementa a obra da acumulação ao colocar os capitalistas industriais em condições de expandir a escala de suas operações. [...] As massas de capital soldadas entre si da noite para o dia pela centralização se reproduzem e multiplicam como as outras, só que mais rapidamente e, com isso, tornam-se novas e poderosas alavancas da acumulação social. (Marx, 1983, p. 197-198).
\end{abstract}

Portanto, na desigual e contraditória relação entre capital e trabalho, o trabalhador sempre estará em desvantagem e, no caso do Brasil, terá a sua força de trabalho sob a égide da superexploração $0^{12}$ e, no caso do pequeno produtor familiar integra-

12 Segundo Ruy Mauro Marini (2000, p. 160), a superexploração do trabalho, "[...] se define mais pela maior exploração da força física do trabalhador, em contraposição à exploração resultante do aumento de sua do, terá, não só a sua força de trabalho, mas, também, a força de trabalho de sua família, sob essa lógica, uma vez que eles participam do movimento de reprodução e acumulação de capital no ramo da agroindústria estudado.

Com a objetivação da parceria, o trabalho dos pequenos produtores familiares se torna, de certa forma, assemelhado à produção fabril. Particularmente na avicultura, que é fundamental para a integração, uma vez que o papel do produtor limita-se a engordar o "pintinho" de um dia - o qual não lhe pertence - até se transformar em frango pronto para o abate, que será realizado pela empresa integradora. Ou seja, o trabalho no sistema de integração pode tanto contemplar uma modalidade típica de produção familiar, quanto basear-se numa forma específica de subordinação desse trabalho ao capital, de que é exemplo o "salário por peça” (Marx, 1988, p. 133), claramente diverso da atividade laborativa típica da pequena propriedade rural voltada para a subsistência.

Segundo Marx (1988, p. 133),

O salário por peça nada mais é que uma forma metamorfoseada do salário por tempo, do mesmo modo que o salário por tempo é a forma metamorfoseada do valor ou preço da força de trabalho. $\mathrm{O}$ trabalho por peça parece, à primeira vista, como se o valor de uso vendido pelo trabalhador não fosse função de sua força de trabalho, trabalho vivo, mas trabalho já objetivado no produto, como se o preço desse trabalho não fosse determinado, como o do salário por tempo, pela fração do valor diário da força de trabalho / Jornada de trabalho de dado número de horas, mas pela capacidade de produção do produtor.

O fato de que o pequeno avicultor não se constitua numa forma de assalariamento clássico (visto que ele é proprietário das ferramentas ne-

produtividade e tende normalmente a expressar-se no fato de que a força de trabalho se remunere por baixo de seu valor real". E, segundo Antunes (1992, p. 145- 146), a superexploração do trabalho ocorre quando "[...] à intensidade extenuante do trabalho acrescia-se o prolongamento da jornada de trabalho. Considerando-se a formulação marxiana de que 'o grau de exploração do trabalho, a apropriação de mais-trabalho, de mais-valia, é elevado a saber por meio de prolongamento da jornada de trabalho e intensificação do trabalho', utilizamos aqui a noção superexploração para enfatizar e precisar a maneira pela qual [...] no Brasil utilizou-se, ao limite, destas duas formas de extração da mais-valia”. 
cessárias para sua atividade), não deve, portanto, impedir que se compreenda o sentido capitalista presente nesta relação de trabalho. No que concerne a este aspecto, as indicações de Marx (1987, p. 384-406) também são seminais e nos auxiliam analiticamente para compreender o processo de trabalho presente no sistema de integração ao afirmar que, no modo de produção capitalista:

O camponês ou artesão independentes são divididos em duas pessoas. 'Nas pequenas empresas o patrão é muitas vezes seu próprio trabalhador'. Como possuidor dos meios de produção é capitalista, como trabalhador é assalariado de si mesmo. Como capitalista paga o salário a si mesmo e extrai o lucro de seu capital, isto é, explora a si mesmo como assalariado e se paga com maisvalia o tributo que o trabalho deve ao capital.

Ainda que estas indicações analíticas se refiram a outra realidade - à gênese do capitalismo clássico -, nos parece uma pista analítica bastante importante para pensar a especificidade do trabalho do pequeno produtor rural inserido no sistema de integração que participa diretamente do processo de valorização do capital.

Assim, podemos indicar que o sistema de Integração, através da falácia própria da lógica capitalista, encoraja o pequeno produtor familiar a se inserir nessa "parceria", acreditando ser a melhor saída para assegurar a venda de sua produção, mas, em verdade, serve, efetivamente, para valorizar o capital das agroindústrias, através da extração do sobretrabalho (dele e de seus familiares). Desse modo, o sistema integrado se assemelha a "uma prisão de portas abertas", conforme o depoimento contundente anteriormente apresentado. A triste metáfora não poderia ser melhor.

Recebido para publicação em 30 de outubro de 2012 Aceito em 10 de dezembro de 2012

\section{REFERÊNCIAS}

ANTUNES, R. A rebeldia do trabalho. Campinas/SP: Editora da UNICAMP, 1992. torial, 1999 .

Os sentidos do trabalho. São Paulo: Boitempo Edi-

BELIK, W. Agroindústria e reestruturação industrial no Bra- sil: elementos para uma avaliação. Cadernos de Ciência \& Tecnologia, Brasília, v.11, n.1/3, p.58-75, 1994.

DALLA COSTA, A. J. A Sadia e as sucessivas sucessões nas empresas familiares. 2005. Disponível em www.economiaetecnologia.ufpr.br/textos discussao/ www.economiaetecnologia.ufpr.br/textos discussao/ em: $2 \overline{7} \cdot 10 . \overline{2} 012$

FERNANDES FILHO, J.F.; QUEIROZ, A.M. Transformações recentes na avicultura de corte brasileira: o caso do modelo de integração. 2006. Disponível em: www.pensaconference.org siteantigo/arquivos_2001/67. Acessado em: 25.11.2011

FRANCO, C. et al. Análise dos contratos na avicultura de corte em Mato Grosso sob a ótica da nova economia institucional. Revista de Economia e Agronegócio, v. 9, n. 2, Viçosa, Universidade Federal de Viçosa, 2011.

GRAZIANO DA SILVA, J. Introdução. In: (Org.) Estrutura agrária e produção de subsistência na agricultura brasileira. São Paulo: Editora HUCITEC, 1980.

. A modernização dolorosa: estrutura, agrária, fronteira agrícola e trabalhadores rurais no Brasil. Rio de Janeiro: Zahar editores, 1982.

HIRATA, H.; DOARÉ, H. Os paradoxos da globalização. Cadernos Sempreviva. O trabalho das mulheres. São Paulo: SOF Sempreviva Organização Feminista, 1999.

JESUS, E. de. O sistema de integração na produção de aves no oeste catarinense: Análise sobre o processo de trabalho e a relação contratual entre a empresa Sadia e avicultores. 2010. 110 p. Dissertação (Mestrado em Serviço Social) Programa de Pós-graduação em Serviço Social da Universidade Federal de Santa Catarina.

LUSA, M. G. Trabalho no contexto rural: quando a divisão sexual do trabalho conforma as tramas da identidade de mulheres e homens da agricultura familiar no Oeste Catarinense. 2008. 159 p. Trabalho de Conclusão de Curso (Graduação em Serviço Social) - Departamento de Serviço Social da Universidade Federal de Santa Catarina.

MARINI, R. M. Dialética da dependência. Petrópolis: Editora Vozes, 2000

MARX, K. O Capital, Livro I / Volume I. Rio de Janeiro: Ed. Civilização Brasileira, 1971.

O Capital: crítica da economia política. Coleção Os Economistas. Vol. I, Tomo I. São Paulo: Abril Cultural, 1983.

O Capital. Coleção Os Economistas. Livro Primeiro / Volume I e II, Tomo I e 2. São Paulo: Ed. Nova Cultural, 1988.

Teorias da mais valia. Livro 4 / Volume 1. São Paulo: Editora Bertrand, 1987. Disponível em: www.marxists.org/portugues/marx/1863/mes/ prodcapital.htm. Acessado em: 26.10.2012

NOGUEIRA, C. M. A feminização no mundo do trabalho. Campinas-SP: Autores Associados, 2004.

OLIVEIRA, F. de. A economia brasileira: crítica à razão dualista. Estudos Cebrap, $n^{\circ}$ 02, São Paulo, S/d. Disponível em: www.cebrap.org.br/v2/files/upload/biblioteca virtual/ a_economia_brasileira.pdf. Acessado em: 26.10.2012

RECHE, D. A influência do capital agroindustrial na distribuição socio-espacial urbana do município de Chapecó no Sul do Brasil. In: ANAIS do X Colóquio Internacional de Geocrítica, Barcelona. 2008.

TEIXEIRA, F. M. P. Sadia, 50 anos construindo uma história. São Paulo : Prêmio Editorial Ltda, 1994.

THOMÁZ JR, A. O metabolismo do capital no campo, em São Paulo: fragmentação e alienação do trabalho. In: BATISTA, R. L e ARAÚJO, R. (Orgs). Desafios do trabalho: capital e luta de classes no século XXI. Londrina: Práxis; Maringá: Massoni, 2003. p. 83-114. 


\section{SMALL FAMILY-RUN POULTRY-RAISING AND THE INTEGRATION SYSTEM IN WESTERN SANTA CATARINA STATE: "an open-door prison"}

\section{Claudia Mazzei Nogueira Edivane de Jesus}

This text is part of a study on the division of labor between sexes in small family-run poultry businesses, linked to the Integration System of the agro-industries, within the context of production restructuring. In order to do so, the text analyzes the aforementioned system in poultry-raising in western Santa Catarina State, contemplating some elements of the changes that have been occurring in the world of work and how these changes have intensified the precarious situation of small family farmers who raise poultry.

KEY WoRDs: Agro-Industry. Labor relations. Small Family Farmer. Integration System. Precariousness.

\section{LA PETITE PRODUCTION AVICOLE FAMILIALE ET LE SYSTEME D'INTÉGRATION DANS LOUEST DE SANTA CATARINA: "une prison aux portes ouvertes"}

\author{
Claudia Mazzei Nogueira \\ Edivane de Jesus
}

Ce travail s'inscrit dans le cadre d'une recherche concernant la division sexuelle du travail des petits aviculteurs familiaux liés au Système d'Intégration de l'agro-alimentaire dans le contexte de la restructuration productive. On y fait l'analyse du système dans l'aviculture de l'ouest de l'état de Santa Catarina, en prenant en considération certains éléments des métamorphoses qui ont lieu dans le monde du travail et en vérifiant comment ceux-ci intensifient la précarisation du petit producteur rural familial du secteur de l'aviculture.

Mots-ClÉs: Agro-alimentaire. Relations dans le Travail. Petit producteur rural familial. Système d’intégration. Précarisation.

Claudia Mazzei Nogueira - Doutora em Serviço Social. Professora do Programa de Pós-Graduação Interdisciplinar da Universidade Federal de São Paulo-UNIFESP-BS. Pesquisadora Bolsa Produtividade CNPq e pesquisa na área de Serviço Social, com ênfase em Relações e Processo de Trabalho, atuando principalmente nos seguintes temas: O mundo do trabalho, a força de trabalho feminina, divisão sexual do trabalho nos espaços da produção e reprodução e saúde do trabalhador. Coordenadora do Núcleo de Estudos do Trabalho e Gênero - NETeG. Publicações recentes: A Produção de conhecimento no Serviço Social. O mundo do trabalho em debate.. Serviço Social \& Sociedade, v. 113, p. 193-195, 2013; A Divisão Sexual do Trabalho no Sistema de Integração Agroindustrial.. Serviço Social \& Sociedade, v. 111, p. 509528, 2012; Capital, trabajo y nueva organización obrera.. 1. ed. Mexico, D.F.: Las Ciencias Sociales; Universidad Autónoma de Nuevo León; Miguel Ángel Porrúa., 2012. v. 1. 352p; O trabalho duplicado. A divisão sexual no trabalho e na reprodução: um estudo das mulheres trabalhadoras no telemarketing. (Editora Expressão Popular), 2011.

Edivane de Jesus - Mestre em Serviço Social pela Universidade Federal de Santa Catarina - UFSC. Graduada em Serviço Social pela Universidade Comunitária Regional de Chapecó-UNOCHAPECÓ. É servidora pública, atua como assistente social no setor de Serviço Social do INSS/SC. 